\title{
Meteor heights during the recent solar minimum
}

\author{
Ch. Jacobi \\ Institute for Meteorology, University of Leipzig, Stephanstr. 3, 04103 Leipzig, Germany \\ Correspondence to: Ch. Jacobi (jacobi@uni-leipzig.de)
}

Received: 19 December 2013 - Revised: 4 February 2014 - Accepted: 10 February 2014 - Published: 10 November 2014

\begin{abstract}
Average meteor heights have been continuously observed using a SKiYMET VHF radar at Collm $\left(51.3^{\circ} \mathrm{N}\right.$, $\left.13.0^{\circ} \mathrm{E}\right)$ since late summer of 2004 . Initially, the daily mean meteor height was about $89.4 \mathrm{~km}$. Since that time, average meteor heights have decreased. This is consistent with earlier results on middle atmosphere temperature change from the literature and from earlier results of low-frequency reflection height changes measured at Kühlungsborn and Collm. During the recent solar minimum 2008/2009 the meteor heights further decreased. Linear fitting of a trend and a solar cycle to the heights reveals a linear decrease of about -56 m year $^{-1}$ and a solar cycle effect of $+450 \mathrm{~m}$ per $100 \mathrm{sfu}$. Assuming that meteor heights, on a long-term average, approximately refer to a level of constant pressure, this decrease can be converted to a mean middle atmosphere linear temperature decrease of $-0.23 \mathrm{~K} \mathrm{year}^{-1}$ and a solar cycle effect of $+1.8 \mathrm{~K}$ per 100 sfu during the last decade, which is in the range of observed trends reported in the literature.
\end{abstract}

\section{Introduction}

The increase of greenhouse gas concentration leads to warming of the troposphere, but cooling of the middle and upper atmosphere (Beig et al., 2003; Lastovicka et al., 2006). This long-term cooling of the stratosphere and mesosphere has been shown by model calculations and has been observed during the last decades also (see, e.g., Beig et al., 2003; Beig, 2011a). It should lead to a decrease of layers of constant pressure in the middle atmosphere (e.g., Lübken et al., 2013). This decrease has been registered using LF phase heights (Bremer and Berger, 2002; Bremer and Peters, 2008), and it was found that the height of radio wave reflections decreases according to mesospheric cooling. For virtual heights of about $95 \mathrm{~km}$ obtained during the time interval 1983-2001, Kürschner and Jacobi (2003) found a de- creasing trend as well. At $\mathrm{E}$ region altitudes, also a decrease of the reference heights with time has been reported (e.g., Hall et al., 2011), at least for the majority of analysed time series (Bremer, 2008). On the decadal time scale, the 11-year solar cycle is one of the most important sources of middle atmosphere variability (e.g., Li et al., 2011; Beig, 2011b). From observations, long-term cooling and solar effect in the mesosphere is found to be dependent on altitude; as an approximate order of magnitude a trend of $-2 \mathrm{~K} \mathrm{decade}^{-1}$ and a solar effect of $+1 \mathrm{~K} 100 \mathrm{sfu}^{-1}$ has been found. It has to be taken into account that these analyses usually do not include the recent strong solar minimum.

A widely used method to observe mesopause region (80$100 \mathrm{~km}$ ) atmospheric parameters are VHF meteor radar (MR) measurements. MR can measure meteor altitudes, Doppler winds, diffusion coefficients, and further parameters (e.g., Hocking et al., 2001; Stober et al., 2012). The observed meteor altitudes depend on the meteor parameters like velocity, entrance angle, meteor mass and composition. In addition, the atmospheric density plays an important role so that meteors on an average reach lower altitudes if the density decreases (e.g., Stober et al., 2012). In the case of progressive cooling of the middle atmosphere, one may therefore expect long-term decrease of mean meteor altitudes. Actually, this may affect long-term trend analyses of winds and tidal parameters, as has been discussed by Merzlyakov and Portnyagin (1999) and Jacobi et al. (2005), for instance.

In the following, 9 years of meteor heights are used to analyse possible height changes during the time interval 20042013. Although the available dataset is much too short to reliably derive long-term trends, tendencies can be detected to support the hypothesis of decreasing meteor altitudes and thus middle atmosphere cooling with time. 


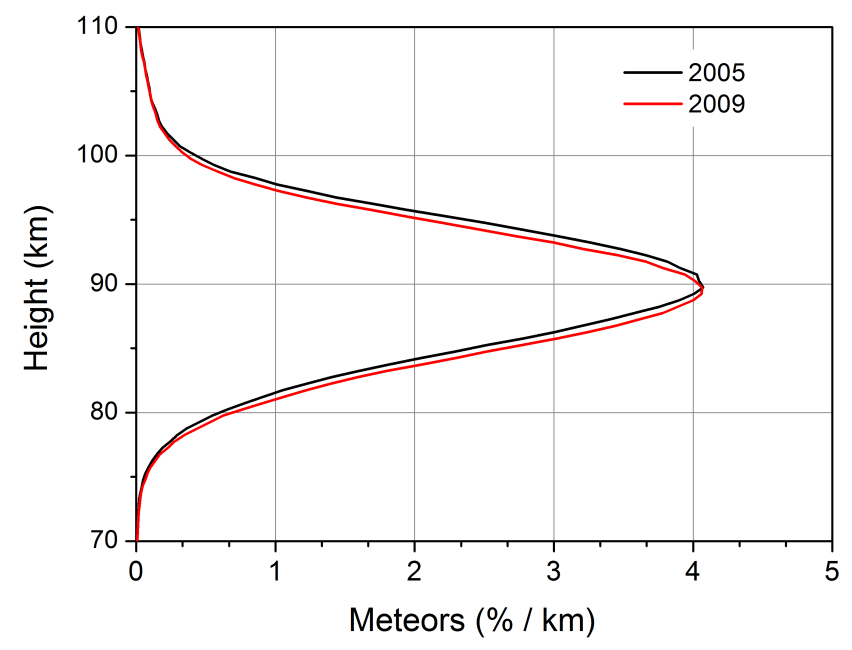

Figure 1. Histograms of meteor heights in 2005 (black) and 2009 (red), given in $\%$ per $1 \mathrm{~km}$ height interval. In total, 1.97 and 2.37 million meteors have been registered in 2005 and 2009, respectively.

\section{Collm meteor radar measurements}

At Collm, Germany $\left(51.3^{\circ} \mathrm{N}, 13.0^{\circ} \mathrm{E}\right)$, a SKiYMET all sky MR is operated at $36.2 \mathrm{MHz}$ since summer 2004. The antenna system consists of one 3-element Yagi transmitting antenna and five 2-element Yagi receiving antennas, forming an interferometer. Peak power is $6 \mathrm{~kW}$. Pulse repetition frequency is $2144 \mathrm{~Hz}$, but effectively only $536 \mathrm{~Hz}$ due to 4 -point coherent integration. The sampling resolution is $1.87 \mathrm{~ms}$. The angular and range resolutions are $\sim 2^{\circ}$ and $2 \mathrm{~km}$, respectively. The pulse width is $13 \mu$ s, the receiver bandwidth is $50 \mathrm{kHz}$.

We consider zenith angles between $0^{\circ}$ and $70^{\circ}$, and distances of up to $400 \mathrm{~km}$ from the transmitter. The height distribution of all individual meteors during two different years is given in Fig. 1. For the present analysis, meteor count rates and mean heights are taken every $2 \mathrm{~h}$. The long-term mean diurnal cycles of mean meteor heights and count rates are shown in Fig. 2. In the following, daily and monthly mean meteor heights are calculated as arithmetic averages of the 2hourly means. Note that these values are lower than the peak heights shown in Fig. 1, owing to the uneven distribution of meteor count rates in the course of a day.

\section{Results}

Monthly mean meteor altitudes, calculated from the 2-hourly mean altitudes are shown in Fig. 3. The red line is a smoothed curve obtained after applying a $6 \mathrm{pt}$ FFT filter. On can see that from the beginning of the registrations until 2009 the heights have decreased by about $500 \mathrm{~m}$. Since then they have remained approximately constant. Minimum altitudes are registered in 2009. During that year, solar activity had reached

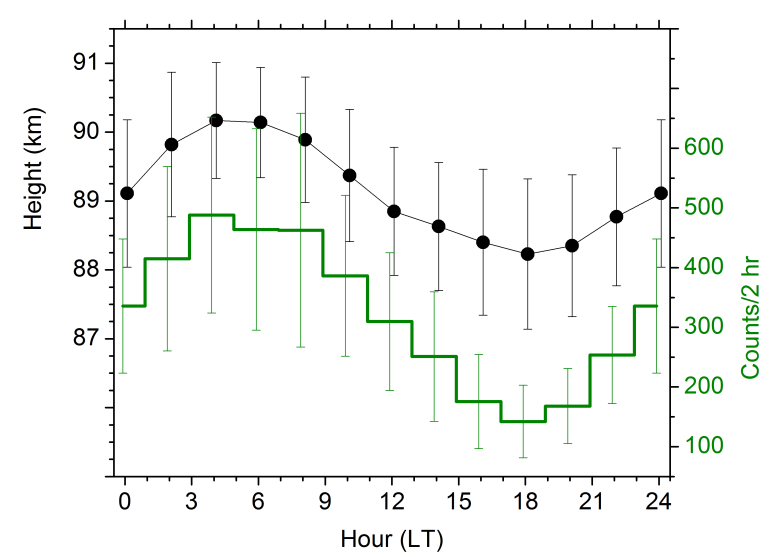

Figure 2. 9 year mean diurnal cycle of 2-hourly mean meteor heights (black) and number of meteors per $2 \mathrm{~h}$ rime interval (green). Data used are from September 2004 through August 2013. Error bars show standard deviations calculated using the $2 \mathrm{~h}$ means.

its minimum in the course of the extended 23/24 solar minimum (e.g., Nikutowski et al., 2011). Since then solar activity has increased again, although the current solar cycle 24 is weaker than previous ones. Meteor heights, however, did not increase again substantially. This is possibly due to the fact that after 2009 a possible increase owing to the increasing solar activity and connected warming of the middle atmosphere is just compensated by a long-term decreasing trend.

To discriminate a possible long-term tendency from a solar cycle effect, annual mean altitudes $z$ were calculated from the monthly means. The time series is shown in Fig. 4 as a black line with squares. Since the measurements have started in summer 2004, annual means are here calculated as averages over the time interval from September through August. A least-squares fit was applied:

$z=z_{0}+a \times t+b \times F$,

with $t$ as the time in years and $F$ as the F10.7 solar flux index in sfu. The obtained coefficients are $a=-56$ mear $^{-1}$ and $b=+450 \mathrm{~m}$ per $100 \mathrm{sfu}$. The annual mean F10.7 values are added in Fig. 4 as a green line. The meteor height time series after subtracting the solar cycle is given as a red line, and the linear trend curve is added. The obtained linear trend is on the order of magnitude of that reported by Bremer and Peters (2008) but smaller than the one obtained from LF heights at Collm (Kürschner and Jacobi, 2003). However, the latter have used virtual heights that overestimate the real heights and therefore the trends as well. The height time series after removing the long-term tendency is shown as blue line in Fig. 4. Clearly, the minimum altitude is found in 2009 during the deep solar minimum.

The annual mean heights plotted vs. the F10.7 solar flux are shown in Fig. 5. Clearly, during the increasing part of solar cycle 24 the meteor heights are lower than during earlier 


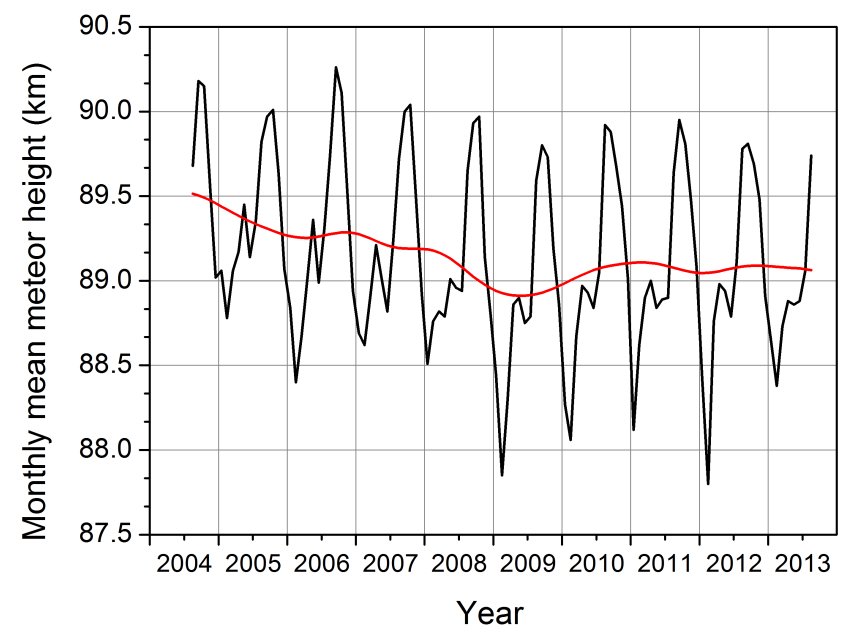

Figure 3. Monthly mean meteor heights, calculated from 2-hourly mean heights. The smoothed curve after applying a 6 pt FFT filter is given in red.

years, i.e. during the decreasing part of solar cycle 23. After removing the long-term tendency (blue line with squares in Fig. 5) the two parts of the height time series, i.e., during the last part of solar cycle 23 and the first part of solar cycle 24 show a good correspondence. One may also note that the difference between 2005 and 2009 amounts to about $-450 \mathrm{~m}$.

\section{Middle atmosphere temperature trends}

Bremer and Berger (2002) had estimated mean middle atmosphere cooling rates from pressure level height decrease by a registered height difference $\Delta z$. Assuming that at the beginning and end of a registration the pressure values $p_{\mathrm{b}}$ and $p_{\mathrm{e}}$ are the same

$p_{\mathrm{b}}(z)=p_{\mathrm{e}}(z+\Delta z)$,

one may use the hydrostatic equation and ideal gas law

$p_{0} \exp \left\{-\frac{g}{R} \int_{z_{0}}^{z} \frac{\mathrm{d} z}{T(z)}\right\}=p_{0} \exp \left\{-\frac{g}{R} \int_{z_{0}}^{z+\Delta z} \frac{\mathrm{d} z}{T(z)+\Delta T}\right\}$,

with $R$ as the gas constant and $g$ as acceleration due to gravity, taken as constant here. The temperature profile $T(z)$ is taken from the CIRA 1986 climatology (Fleming et al., 1990). Assuming a constant temperature change $\Delta T$ with height and no height change at some lower boundary $z_{0}$, one obtains

$$
\int_{z_{0}}^{z} \frac{\mathrm{d} z}{T(z)}=\int_{z_{0}}^{z+\Delta z} \frac{\mathrm{d} z}{T(z)+\Delta T}
$$

which can be solved for $\Delta T$. Note that Bremer and Berger (2002), taking the temperature change height distribution

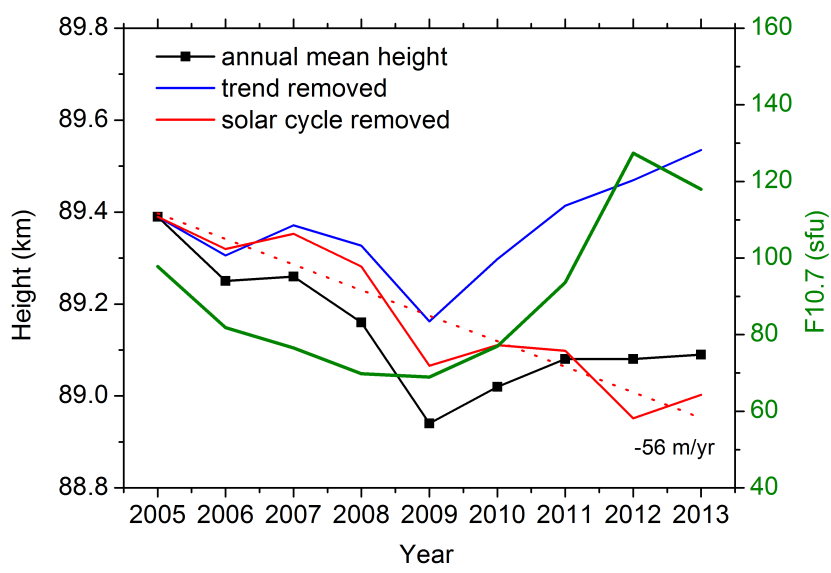

Figure 4. Annual mean meteor heights (black curve). The annual mean F10.7 values are added as green line. The blue and red lines represent annual means after removing the decadal trend or solar effect, respectively. The dotted red line is a linear fit to the annual means after removing the solar cycle. The annual means refer to the time interval from September of the previous year through August.

from literature results, were able to obtain a vertical profile of temperature change. Since, however, this requires external input this is not done here. Here, $z_{0}=20 \mathrm{~km}$ is assumed, and the resulting mean middle atmosphere temperature tendencies are $-2.3 \mathrm{~K} \mathrm{decade}^{-1}$ for the long-term tendency and $+1.8 \mathrm{~K}$ per $100 \mathrm{sfu}$ for the solar cycle effect. According to a $t$ test, the trends are significant at the $95 \%$ or $90 \%$ level for the long-term decrease and the solar cycle effect, respectively. The results do not much depend on the temperature profile $T(z)$ chosen. This is, because the change in temperature is small compared with the mean temperature itself, and differences between climatologies (CIRA, MSIS, ...) are of the order of few percent. For example, using NRLMSISE00 predictions (Picone et al., 2002) delivers the same result (at an accuracy of $0.1 \mathrm{~K}$ ), and even in the extreme case of temperatures taken as constant with height the trends do not change by more than $10 \%$.

\section{Discussion and conclusions}

From the analysis of 9 years of meteor altitudes one may find a long-term decreasing tendency and a possible solar cycle effect. The trend values are within the range of reported middle atmosphere temperature trends (Li et al., 2011; Beig, 2011a) and solar cycle effects (Beig, 20011b). However, most values of observed trends reported in the literature are based on time series that do not include the deep solar minimum 23/24 and therefore numbers may differ in detail.

In contrast to the reported decreasing trends, model calculations by Berger and Lübken (2011) and Lübken et al. (2013) show positive temperature trends in summer over Germany since the middle 1990s. They attribute this increase to the increase of stratospheric ozone since then. This is, 


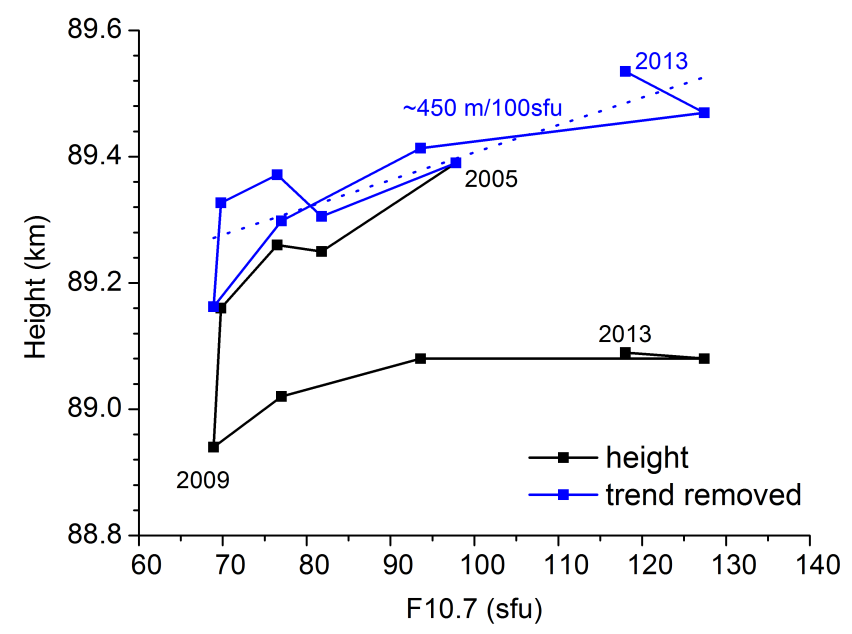

Figure 5. Annual mean meteor heights vs. annual mean F10.7 solar radio fluxes (black curve). The blue values represent annual means after removing the decadal trend. The dotted blue line is a linear fit to the annual means after removing the trend. The indicated years denote the time interval from September of the previous year through August.

to a certain degree, consistent with analyses of Jacobi and Kürschner (2007), who had used an updated dataset from Kürschner and Jacobi (2003), and who found that during the early 2000s the LF reflection heights did not decrease. However, the LF measurements at Collm have been interrupted in 2007, so that these results cannot be compared with the MR heights. Offermann et al. (2010), on the other hand, showed negative mesopause region temperature trends derived from $\mathrm{OH}^{*}$ temperatures over Wuppertal, however, they also reported that these trends in summer are smaller compared to the winter ones. Hall et al. (2012) also reported decreasing temperatures in the high latitude mesopause region during the last decade. One may conclude that there are observations that indicate a continuing cooling of the middle atmosphere, but there is still debate on this point.

The here analyzed time series is very short and therefore no definite quantitative conclusions on real trends and in particular on the relative role of solar and long-term trend effects can be drawn. In addition, results from such a short time series cannot be extrapolated, even if they are significant in a purely statistical sense. On the other hand, the obtained tendencies for the mean altitudes at least qualitatively confirm most tendencies reported in the literature, which shows that MR heights may be used as an indicator for middle atmosphere temperature trends.

Acknowledgements. F10.7 solar indices have been provided by NGDC through ftp://ftp.ngdc.noaa.gov/STP/SOLAR_DATA/. CIRA temperatures have been provided by BADC through http://www.badc.nerc.ac.uk/data/cira. NRLMSISE00 data has been provided by CCMC, GSFC, NASA on http://ccmc.gsfc.nasa.gov/modelweb/.
Edited by: M. Förster

Reviewed by: two anonymous referees

\section{References}

Beig, G.: Long-term trends in the temperature of the mesosphere/lower thermosphere region: 1. Anthropogenic influences, J. Geophys. Res., 116, A00H11, doi:10.1029/2011JA016646, 2011a.

Beig, G.: Long term trends in the temperature of the mesosphere/lower thermosphere region: 2. Solar response, J. Geophys. Res., 116, A00H12, doi:10.1029/2011JA016766, 2011 b.

Beig, G., Keckhut, P., Lowe, R. P., Roble, R. G., Mlynczak, M. G., Scheer, J., Fomichev, V. I., Offermann, D., French, W. J. R., Shepherd, M. G., Semenov, A. I., Remsberg, E. E., She, C. Y., Lübken, F. J., Bremer, J., Clemesha, B .R., Stegman, J., Sigernes, F., and Fadnavis, S.: Review of mesospheric temperature trends, Rev. Geophys., 41, 1015, doi:10.1029/2002RG000121, 2003.

Berger, U. and Lübken, F.-J.: Mesospheric temperature trends at midlatitudes in summer. Geophys. Res. Lett., 38, L22804, doi:10.1029/2011GL049528, 2011.

Bremer, J.: Long-term trends in the ionospheric E and F1 regions, Ann. Geophys., 26, 1189-1197, 2008, 2008.

Bremer, J. and Berger, U.: Mesospheric temperature trends derived from ground-based LF phase-height observations at midlatitudes: comparison with model simulations, J. Atmos. Sol.Terr. Phy., 64, 805-816, 2002.

Bremer, J. and Peters, D.: Influence of stratospheric ozone changes on long-term trends in the meso- and lower thermosphere, J. Atmos. Sol.-Terr. Phys., 70, 1430-1440, doi:10.1016/j.jastp.2008.03.024, 2008.

Fleming, E. L., Chandra, S., Barnett, J. J., and Corney, M.: Zonal mean temperature, pressure, zonal wind and geopotential height as function of latitude, Adv. Space Res., 10, 11-59, 1990.

Hall, C. M., Rypdal, K., and Rypdal, M.: The E region at $69^{\circ} \mathrm{N}$, $19^{\circ}$ E: Trends, significances, and detectability, J. Geophys. Res., 116, A05309, doi:10.1029/2011JA016431, 2011.

Hall, C. M., Dyrland, M. E., Tsutsumi, M., and Mulligan, F. J.: Temperature trends at $90 \mathrm{~km}$ over Svalbard, Norway $\left(78^{\circ} \mathrm{N} 16^{\circ} \mathrm{E}\right)$, seen in one decade of meteor radar observations, J. Geophys. Res., 117, D08104, doi:10.1029/2011JD017028, 2012.

Hocking, W. K., Fuller, B., and Vandepeer, B.: Real-time determination of meteor-related parameters utilizing modern digital technology, J. Atmos. Sol.-Terr. Phy., 63, 155-169, 2001.

Jacobi, Ch. and Kürschner, D.: Possible climate change response of the mesosphere/lower thermosphere region, Proceedings of the International Symposium "Atmospheric Physics: Science and Education”, St. Petersburg, 11.-13.9.2007, 33-37, 2007.

Jacobi, Ch., Portnyagin, Yu. I., Merzlyakov, E. G., Solovjova, T. V., Makarov, N. A., and Kürschner, D.: A long-term comparison of mesopause region wind measurements over Eastern and Central Europe, J. Atmos. Sol.-Terr. Phy., 67, 227-240, 2005.

Kürschner, D. and Jacobi, Ch.: Quasi-biennial and decadal variability obtained from long-term measurements of nighttime radio wave reflection heights over central Europe, Adv. Space Res., 32, 1701-1706, doi:10.1016/S0273-1177(03)90465-0, 2003. 
Lastovicka, J., Akmaev, R. A., Beig, G., Bremer, J., and Emmert, J. T.: Global Change in the Upper Atmosphere, Science, 314, 1253-1254, doi:10.1126/science.1135134, 2006.

Li, T., Leblanc, T., McDermid, I. S., Keckhut, P., Hauchecorne, A., and Dou, X.: Middle atmosphere temperature trend and solar cycle revealed by long-term Rayleigh lidar observations, J. Geophys. Res., 116, D00P05, doi:10.1029/2010JD015275, 2011.

Lübken, F.-J., Berger, U., and Baumgarten, G.: Temperature trends in the midlatitude summer mesosphere, J. Geophys. Res., 118, 13347-13360, doi:10.1002/2013JD020576, 2013.

Merzlyakov, E. G. and Portnyagin, Y. I.: Long-term changes in the parameters of winds in the midlatitude lower thermosphere (90100 km), Izvestiya, Atmos. Ocean. Phys., 35, 428-493, 1999.

Nikutowski, B., Brunner, R., Erhardt, Ch., Knecht, St., and Schmidtke, G.: Distinct EUV minimum of the solar irradiance (16-40 nm) observed by SolACES spectrometers onboard the International Space Station (ISS) in August/September 2009, Adv. Space Res., 48, 899-903, 2011.
Offermann, D., Hoffmann, P., Knieling, P., Koppmann, R., Oberheide, J., and Steinbrecht, W.: Long-term trends and solar cycle variations of mesospheric temperature and dynamics, J. Geophys. Res., 115, D18127, doi:10.1029/2009JD013363, 2010.

Picone, J. M., Hedin, A. E. Drob, D. P., and Aikin, A. C.: NRLMSISE-00 empirical model of the atmosphere: Statistical comparisons and scientific issues, J. Geophys. Res., 107, 1468, doi:10.1029/2002JA009430, 2002.

Stober, G., Jacobi, Ch., Matthias, V., Hoffmann, P., and Gerding, M.: Neutral air density variations during strong planetary wave activity in the mesopause region derived from meteor radar observations, J. Atmos. Sol.-Terr. Phy., 74, 55-63, doi:10.1016/j.jastp.2011.10.007, 2012. 